treaty (never ratified) would be re-negotiated so that the treaty could be put successfully to the US Senate; why not, at the same time, reduce the limit on explosive power from 150,000 to 10,000 tonnes of TNT equivalent and, at the same time, persuade France and China to join up? Or why not dust off some of the proposals for creating demilitarized zones in Central Europe, of which little has been heard since the early 1960s?

\section{Record-breakers vanish}

This year's Olympics will probably see few records broken. Why not improve the supply?

THE quadriennial trauma of the world's sensibilities represented by the Olympic Games now unfolding in Soeul, South Korea, should not be allowed to conceal the difficulties with which this peripatetic institution will sooner or later have to grapple. For the supply of record-breaking performances is steadily decreasing, so that the organizers must be alarmed that there may not be in future years enough of them to persuade 200,000 visitors to faraway cities and to keep 1,000 times as many people glued to their television screens for two weeks.

Appearances to the contrary notwithstanding, athletic performance is a physiologically determined phenomenon which, as time goes on, will be increasingly governed by statistical considerations. As time goes by, world records will become increasingly rare. For those who enter competitions for jumping high, or long, or for throwing pieces of wood or lead as far as possible, are presumably members of the general population with a natural aptitude for doing what the competition requires and who have been trained to perform consistently. (Much the same is true of those who compete at running quickly over predetermined distances, except that foot-races involve tactical considerations, on-line calculations of how other runners are performing, which complicates the problem.) They cannot escape the underlying statistical character of their work.

The natural performance of individuals may be plausibly supposed to be randomly distributed within the general population. The distribution will have a long tail towards the highperformance end and will be markedly skewed. (Some people can really jump, most can hardly get off the ground.) Similarly, the performance of untrained people with athletic pretensions will be statistically distributed, from one performance to another, and will again have a long tail towards the highperformance end. (Most performances will be mediocre, some will be remarkable.) While trainers would no doubt claim that their function is to improve on nature, the much more probable benefit of their endeavours is to make their charges perform more consistently.

What those who have travelled to Soeul should now appreciate, is that there must be, now and in the years ahead, a growing scarcity of world records to be witnessed. Especially for well-established competitions such as jumping, the potential record breakers are those with exceptional ability among the general population, which has now been well worked over. It must be expected that, from time to time, individuals outstanding by contemporary standards will be discovered, but of necessity those must be increasingly rare events. And the effect of training, by reducing the standard deviation of an individual's performance-distribution, will be to rob these competitions of the surviving element of chance.

The International Olympic Committee seems well aware of this dismal prospect, having this year attempted to import collective sports such as baseball into the programme. The surprise is that it has not sought to keep the world records flowing more readily by more accurate measurement of competitors' performances. High-jumps, which tend now to be callibrated in centimetres, might be enlivened if the measurements were made accurate to the nearest milliemtre or even micrometre.

\section{Genome monitoring}

The organization to monitor the human genome project should be welcomed.

THE gibe that a substantial part of the 3,000 man-years of effort required to sequence the whole human genome has already been spent on discussions of the project is manifestly unfair, but is nonetheless significant. That people are still talking, not just getting on with the job, is a pointer not so much to the technical complexity of the project as to its social and political ramifications. It makes good sense that the difficulties that lie ahead should be anticipated.

That is the spirit in which the quaintly named organization christened HUGO should be welcomed (see page 286). So far as can be told, the objective is that HUGO should be an independent international body of selfappointed people whose interest is to encourage the genome project, to monitor progress and to anticipate problems. While HUGO hopes to find some funds to spend on modest enterprises, they are bound to be a tiny fraction of what will need to be spent on the production of nucleotide sequences of DNA from human and other genomes. The trick that HUGO hopes to play is that of influencing the policies of governments and of international and national institutions. Success will depend on being smarter than the governments that will eventually have to pay for the project.

Perhaps the place to start is with a definition of what the human genome project consists of. The simple notion that it will suffice to take the chromosomes from one person's cells and sequence the DNA from end to end is of course absurd, witness the gibe "Whose DNA?" The potential benefits of a successful project in this field are epitomized by the prospect that it will become easier to identify genes implicated in genetic diseases, but that is a small part of the tale there may be one day to tell. It is surely even more significant that the ideal product of a sequencing project should illuminate in ways not otherwise possible the crucial questions about the functioning of aggregates of genes, and about their evolution. For that purpose, the sequence of a single genome will not suffice. The variable parts of the human genome will have to be described and understood.

The good reason why people have not so far buckled down to the task of sequencing is that the scale on which these questions must be answered is not yet understood. The moral, for governments, is that the human genome project is not exclusively human and not a once-and-for all project. Their response should be much as it has been so far - supporting technical developments that may accelerate and even automate routine sequencing, assisting with the discussion of problems, scientific and technical, and brooding about the policy questions that arise. But this phase should soon be coming to an end. What the world needs is a number of small laboratories primarily skilled at sequencing that will also serve as foci for planning the way ahead. HUGO is probably well placed to help them coordinate their work, avoiding the danger that the project might become a kind of international competition, as to the Moon.

The policy questions are more difficult. For example, there is something in the view, shared by many, that resources spent on sequencing will be taken from other worthwhile projects in biology; the best answer is to demonstrate that the sequencing project itself will yield equal benefits. The ethical issues are more shadowy. Plainly, difficulties would arise, for example, if people carrying deleterious genes were able to tell their own status by referring to a sufficiently detailed genetic map. Physicians rightly ask that people carrying Huntington's disease should not be so informed without counselling. The more common worry, that there may be something about the constitution of the human genome that could be misused, is probably illfounded but must nevertheless be countered intelligently if the project is to succeed. If HUGO can do this, it will be well worthwhile. 